\title{
NARRATIVA DO CUIDAR EM PARTO HUMANIZADO
}

\author{
Jéssica Lopes de Oliveira ${ }^{1}$, Luciana Segurado Cortes ${ }^{2}$, Marcella da Nóbrega Santiago ${ }^{3}$ e \\ Antônio Carlos Rodrigues da Cunha ${ }^{4}$

\footnotetext{
${ }^{1,2 \text { e } 3}$ Secretaria de Estado de Saúde do Distrito Federal, Brasil, ${ }^{1}$ jess.loli@hotmail.com

2lucianasegurado@yahoo.com.br ${ }^{3}$ marcellasantiagonobre@hotmail.com

${ }^{4}$ Conselho de Ética em Pesquisa Universidade de Brasília, Brasil. acrc@unb.br
}

\begin{abstract}
Resumo. Por meio de um relato de caso pretende-se utilizar a metodologia da Medicina narrativa para refletir acerca do papel da narrativa da experiência de parto humanizado em posição ortostática (em pé), vivenciada de forma inédita por médica residente do primeiro ano de Ginecologia e Obstetrícia em um hospital público do Distrito Federal (Brasil), avaliando o seu impacto no aprimoramento da relação médico-paciente, valorizando os que anseiam cuidados e permitindo maior organização das necessidades dos mesmos.
\end{abstract}

Palavras-chave: Medicina Narrativa; Relato de Caso; Parto Humanizado.

\section{NARRATIVE OF CARE IN HUMANIZED DELIVERY}

Abstract. Through a case report we intend to use the methodology of narrative medicine to reflect on the role of the narrative of the experience of humanized childbirth in an orthostatic position (standing), experienced in an unprecedented way by a resident doctor of the first year of Gynecology and Obstetrics in a public hospital in the Federal District (Brazil), assessing its impact on improving the doctor-patient relationship, valuing those who crave care and allowing greater organization of their needs.

Keywords: Narrative Medicine; Case Report; Humanized Birth.

\section{INTRODUÇÃO}

O parto, segundo Dias em 2006, é o conjunto dos fenômenos mecânicos ou fisiológicos que culminam na saída do feto e de seus anexos do organismo materno. A humanização é bastante diversificada e defendida por Moura et al. em 2007, como um processo que respeita a individualidade das mulheres, colocando-as como protagonistas e buscando uma adequação da assistência à cultura, crenças, valores e diversidades de opiniões.

Neste contexto, para Dias em 2006; Diniz em 2005, entende-se que a assistência ao parto deve ser humanizada, designando assim uma forma de cuidar mais atenta, com vistas a melhorias no atendimento, compreendendo o parto como uma experiência humana e, para quem o assiste, uma mudança no "que fazer" diante do sofrimento do outro humano.

Para Porto, Costa e Veloso em 2015, nas políticas públicas na área de Saúde da Mulher, considera-se a humanização da assistência, defendendo uma nova perspectiva em que os cuidados prestados devem ser efetivamente benéficos, as intervenções desnecessárias 
devem ser evitadas e a privacidade, bem como a autonomia materna, devem ser preservadas.

Já o Ministério da Saúde (MS), em 2017, define em sua Diretriz Nacional de Assistência ao Parto Normal, que as boas práticas de amparo à gestante durante o trabalho de parto, são divididas em assistência ao primeiro, segundo e terceiro períodos do parto.

Durante o primeiro período do parto, que é definido pela modificação do colo uterino com dilatação e contrações efetivas, o MS 2017, orienta indagar à mulher como ela está e sobre os seus desejos, expectativas e preocupações; oferecer orientação e apoio para o(s) acompanhante(s) da mulher, pelos quais tem direito e analgesia não medicamentosa como massagem, aromaterapia, banho quente e exercícios de agachamento. Também se deve evitar enema (lavagem intestinal), tricotomia (retirada manual de pelos) e amniotomia precoce (ruptura artificial da bolsa amniótica). Além disso, as mulheres devem ser encorajadas a se movimentarem e adotarem as posições que lhes sejam mais confortáveis no trabalho de parto.

Durante o segundo período, conceituado entre a dilatação máxima do colo uterino e expulsão fetal, o MS 2017 expõe que a grávida deve ser incentivada a adotar qualquer posição que ela achar mais confortável incluindo as posições de cócoras, lateral ou quatro apoios. Está proscrita a episiotomia (incisão efetuada no períneo para ampliar o canal de parto) de rotina durante o parto vaginal espontâneo.

O terceiro período do parto é o momento desde o nascimento até a expulsão da placenta e membranas. Nesse instante, o MS 2017 orienta reconhecer que o período imediatamente após o nascimento é bastante sensível, quando a mulher e seus acompanhantes vão finalmente conhecer a criança. $O$ profissional deve assegurar que a assistência e qualquer intervenção que for realizada levem em consideração esse momento, no sentido de minimizar a separação entre mãe e filho. Para conduta não preconiza o uso rotineiro de uterotônicos (medicações para contração uterina); é incentivado o clampeamento do cordão após parar a pulsação e expulsão da placenta por esforço materno, sem tração manual do cordão.

Em complementação, a Organização Mundial de Saúde (OMS) em 2019 recomenda, ainda, monitoramento do bem-estar físico e emocional da mulher durante o trabalho de parto e ao término do processo de nascimento. Também orienta oferta de líquidos por via oral durante 
o trabalho de parto e parto, respeito à escolha da mãe sobre o local do parto, ao direito da mulher à privacidade, liberdade de posição e movimento durante o trabalho de parto e, por fim, amamentação imediata após o nascimento sem intercorrências.

\section{PERGUNTA DA PESQUISA}

Qual é o papel da narrativa médica de um parto humanizado para o aprimoramento da relação médico-paciente em Ginecologia e Obstetrícia?

\section{OBJETIVOS}

Analisar qualitativamente o relato de parto humanizado, em posição ortostática, de uma paciente atendida na unidade de Pronto Socorro de Ginecologia e Obstetrícia do Hospital Regional Leste, da Secretaria Estadual de Saúde do Distrito Federal, a partir da narrativa médica dos sentimentos e vivências gerados durante esse atendimento na médica assistente e pesquisadora, residente de Ginecologia e Obstetrícia desse hospital.

\section{METODOLOGIA}

A metodologia utilizada para o estudo de caso dessa pesquisa foi a Medicina Narrativa. Trata-se de uma abordagem descritiva, transversal e qualitativa que, visa, primordialmente, descrever as características de determinada população ou fenômeno e estabelecer relações entre as variáveis de interesse, enunciado por Gil em 2002.

A obtenção dos dados foi realizada a partir das anotações em prontuário e o relato subjetivado da pesquisadora, que é a médica residente de Ginecologia e Obstetrícia e estava no primeiro ano de residência. Houve dispensa do Termo de Consentimento Livre e Esclarecido, já que a coleta de dados foi realizada por meio de consulta a prontuário eletrônico, no sistema track care, portanto, não incorrendo em risco da identificação da paciente.

A narrativa por Claro e Mendes em 2018 é uma forma linguística caracterizada por uma sequência longitudinal necessitando de um narrador e um ouvinte com suas próprias definições da história contada. Pela medicina narrativa ela é importante na elaboração de diagnósticos médicos que hoje são colocados em segundo plano devido à medicina voltada para a doença. Com essa abordagem, a narrativa tem eficácia na relação médico-paciente, estimulando a proximidade entre os dois grupos e melhorando a didática de aprendizado. 
Para De Benedetto e Gallian em 2018, a utilização da Medicina Narrativa traz reflexões a respeito da importância do cuidado com o paciente e da escuta. O fundamento dessa técnica consiste em escutar as histórias dos pacientes com atenção e empatia, mesmo aquelas que aparentemente nada tenham a ver com suas histórias clínicas, e utilizá-las como instrumento terapêutico e didático. Podem ser relatos de experiências pessoais ou narrativas sobre doenças e Medicina. Os relatos médicos de cada caso particular envolvem subjetividades autorais, visto que o material é selecionado e organizado com o intuito de adquirir coerência. Para isso, os registros de anamneses em prontuários e as descrições de casos clínicos englobam reflexão, interpretação, elucubração e pontos de vistas subjetivos.

Neste sentido, Favoreto em 2004; Camargo Jr. em 1997 relatam que as intervenções tradicionais na clínica, como o diagnóstico realizado com base em uma anamnese restrita à coleta de sinais e sintomas das doenças e sob uma perspectiva da terapêutica restrita à prescrição de fármacos, têm dificultado a compreensão dos problemas e significados envolvidos no processo de adoecimento, assim como a adesão dos pacientes aos programas terapêuticos oferecidos.

A narrativa médica segundo Charon em 2004 busca trazer competências para reconhecer, absorver, interpretar e sensibilizar-se através da história relatada pelo paciente, conduzindose casos humanizados, excedendo o modelo de diagnóstico e tratamento focados na doença. Charon em 2004; Frank em 1995 referem que o desenvolvimento da narrativa no processo clínico-terapêutico, como na psicanálise, pode adquirir papel terapêutico central. Ao achar as palavras capazes de expressar as desordens e os medos delas decorrentes, a pessoa dá forma e exerce controle sobre o caos e as rupturas provocadas pela enfermidade.

Associado à medicina narrativa, Bakhtin em 2004 expõe que as palavras e as formas de comunicá-las permitem trazer à tona o mundo interior, isto é, expressar os significados produzidos pela consciência individual e construídos no contexto social no qual o indivíduo se realiza como pessoa. Deste modo, a palavra e a enunciação por ela expressa teriam o papel de materializar a vida semiótica interior.

Para definição, Cassel e Symon em 1994 referem existir alguns métodos mais apropriados para coleta e análise qualitativa: entrevistas abertas, observação participante, análise documental (cartas, diários, impressos, relatórios), estudos de caso, história de vida. Mais do que tais métodos, interessam-nos aqui as características básicas da pesquisa qualitativa 
defendida por Dalfovo, Lana e Silveira em 2008, que inclui ênfase na subjetividade ao invés da objetividade: se aceita que a busca da objetividade é um tanto quanto inadequada, já que o foco de interesse é justamente a perspectiva dos participantes e a flexibilidade no processo de conduzir a pesquisa. Segundo Moreira em 2002, o pesquisador qualitativo pauta seus estudos na interpretação do mundo real, preocupando-se com o caráter hermenêutico na tarefa de pesquisar sobre a experiência vivida dos seres humanos. Diante dessa exposição, optou-se por utilizar a metodologia de Medicina narrativa para registrar os sentimentos e emoções da pesquisadora na condução do parto humanizado.

\section{RELATO DO CASO}

Em uma noite tumultuada de plantão de Obstetrícia, sem vagas para muitas internações, recepcionei uma gestante de 38 anos, com 38 semanas de gestação, em franco trabalho de parto. À primeira impressão, a paciente parecia nervosa e exausta. Orientei internação e me coloquei à disposição para acompanhá-la. Agradecida, ela aceitou, afinal já era a segunda gestação e a primeira teve mau passado obstétrico. Sofreu um estupro, gestação com rejeição ao feto e desejo de parto vaginal sem contato visual com a criança, entregando-a à adoção imediatamente. Durante o trabalho de parto atual, apresentou um período expulsivo prolongado, acompanhado de dor intensa e equipe multiprofissional ao seu lado para garantir que a decisão de realizar o parto em posição ortostática (em pé) fosse cumprida. Logo no início me informou que não gostaria de ser acompanhada por muitos profissionais, pois se recordava do primeiro parto e que, na maior parte do tempo, gostaria apenas da companhia do esposo. Respeitei a vontade da paciente e a avaliei a cada hora como orientado em protocolos obstétricos. O trabalho de parto avançava rapidamente e logo iniciaram contrações efetivas com duração de mais de quarenta segundos. Nesse momento, ensinei-a a se exercitar na bola de Pilates suíça e fazer agachamento para adiantar o parto. Notei felicidade e conforto, pois a paciente praticou atividade física (Pilates) durante toda a gestação. Devido à dor intensa, orientei banho quente para alívio não medicamentoso da dor. A paciente parecia acolhida, principalmente pelo engajamento do marido durante o processo, efetivando a qualidade de parto humanizado. Senti a confiança aumentando com o tempo e fui surpreendida pelo desejo do parto em pé. A princípio, fiquei apreensiva e ansiosa, porque apesar de saber a teoria, nunca havia feito essa modalidade de parto. Porém, a paciente tem o direito de escolher como parir. Assim, fiquei de cócoras para facilitar o posicionamento da parturiente, com o acompanhante situado atrás dela para ser o apoio no parto. O período expulsivo durou trinta minutos em média, sem intercorrências ou 
lacerações. Após expulsão, entreguei o bebê para a mãe ainda ligado ao cordão umbilical. Ela foi inundada por emoção, agradeceu-me pelo acolhimento e cumprimento do desejo do parto, deixando-me comovida. Com o filho nos braços, a mãe caminhou até o leito e esperou até à parada de pulsação do cordão para amamentar de imediato. Naquele momento, ultrapassei a barreira médica para alcançar a afetividade, emoção e superar o medo do procedimento inédito.

\section{DISCUSSÃO}

A abordagem da narrativa, focada na experiência inédita diante do momento repleto de ansiedade e receio materno com desfecho favorável acarretou um crescimento pessoal e profissional marcantes.

Em uma narrativa "completa", segundo Riessman em 2008, há um resumo da história, sua localização (tempo, lugar, situação, participantes), o desenrolar dos eventos, sua avaliação, sua resolução e uma coda - um retorno ao presente do narrador. No caso apresentado completa-se a narrativa, somando os fatos apresentados e a elevação profissional da residente obstetra que expõe o crescimento pessoal e modificação definitiva da relação médico-paciente, visto que esse fato ocorreu no primeiro ano de residência e, portanto, influenciou em tantos outros partos futuros, com maior demonstração de respeito e valorização dos desejos de suas pacientes.

No âmbito da História oral, por Gomes em 2019, o que prevalece nas entrevistas feitas é a subjetividade de quem expõe sua vida, dando relatos do que viveu, como se vê na própria história e como vê quem a rodeia. E, nesse caso, por ser uma vivência de parto, deve-se lidar com questões emocionais da própria paciente. Portanto, cabe à profissional identificar e respeitar as perspectivas pessoais da parturiente.

Identificar as crenças em relação a cada prática de cuidado e fornecer a devida orientação a esse respeito são ações que devem fazer parte do cotidiano do cuidado na assistência às parturientes. Atuando desse modo, o profissional capta a perspectiva das mulheres e a considera na assistência. Esse conjunto de ações promove a conscientização e a consequente efetividade das práticas de autocuidado desenvolvidas no trabalho de parto relembradas por Jamas e Reberte em 2013. 
Para Charon e Montello em 2002, o profissional precisa dar sentido à narrativa do paciente e sua linguagem simbólica, compreender o significado das histórias e imaginar a doença pela perspectiva do doente, muitas vezes contraditória. As narrativas de pacientes abordam aspectos da vida, discussões sobre a doença e desequilíbrios por ela impostos e, especialmente, são apresentados depoimentos sobre as capacidades individuais de agir para transformar essas novas realidades.

Dessa forma, segundo essa metodologia, pode-se inferir o princípio da autonomia com respeito às necessidades e desejos da paciente. Assim como a abordagem narrativa por parte da parturiente, que teve liberdade de expressão e exigências indo de acordo com as propostas de parto humanizado, defendidas pela OMS em 2019 e MS em 2017 e da residente que expôs opinião, conceitos, emoções e crescimento pessoal.

Faz-se importante o ato de narrar segundo Rezende em 2019, porque a análise da estrutura de uma narrativa pessoal revela não apenas questões em torno da experiência, como uma construção subjetiva, as emoções e a agência envolvidas, bem como temas mais amplos da vida social. Podem ser relatos de experiências pessoais ou narrativas sobre doenças e Medicina. Os relatos médicos de cada caso particular envolvem subjetividades autorais, visto que o material é selecionado e organizado com o intuito de adquirir coerência.

Portanto, a partir desse relato despertou na pesquisadora emoções positivas e satisfação por ter realizado o desejo da parturiente na escolha da posição desejada para o parto, valorizando a presença do acompanhante, das manobras não-farmacológicas da dor (uso da bola e massagens); da oportunidade do contato pele a pele com o recém-nascido e da amamentação na primeira hora de vida. Assim, estabeleceu-se uma relação médicopaciente eficaz e engrandecedora para a residente, porque além de respeitar a autonomia da paciente, houve o cuidado em seguir as diretrizes propostas pelo Ministério da Saúde e OMS.

\section{CONCLUSÃO}

Por Gomes em 2019, dentro do processo de parto interpreta-se em diversos discursos historiográficos a mulher como sujeito ativo e responsável por expelir o feto quando este é de forma natural. Porém, apesar de tamanha ansiedade, não é uma responsabilidade única, urgindo uma equipe multiprofissional adequada que respeite suas decisões e possa conduzir humanamente o trabalho de parto. 
Nesse contexto, são discutidos sinais, sintomas, diagnósticos e tratamentos das concepções, sendo necessária aproximação com o modelo humanizado do parto, respeitando as diretrizes regentes dos órgãos de saúde.

Como sugerem Carson et al. em 2017, é no hospital, especialmente na sala de parto, que a mulher se torna mãe sob o olhar público, recebendo crítica ou apoio dos profissionais e familiares presentes. É fato existirem comoções de ambos os lados que são suprimidos, devido à pressa em diagnosticar o motivo da procura médica, omitindo sentimentos, questionamentos, apreensões, medos e inseguranças. Principalmente medo de errar e ser julgado por outros profissionais, assim como, pelo paciente por parte do médico. E medo de se expor e não ser compreendido por parte do enfermo.

Mas, ao narrar uma experiência, os profissionais de saúde dão voz aos sedentos de tratamento, permitindo maior organização das necessidades da paciente, culminando em um círculo diagnóstico que poderá ser usado coletivamente com outros profissionais. Assim, faz-se necessária maior comunicação entre as partes e exposição de emoções, lançando mão das teorias prontas para cada comorbidade e abrindo oportunidades para entendimento das singularidades e diversidades atreladas a contextos socioculturais plurais.

Conclui-se que a importância desse estudo consiste na possibilidade de utilizar a Medicina narrativa para registrar as emoções da pesquisadora diante de uma situação inusitada para a mesma, o parto em posição ortostática, e permitir o exercício do cuidado qualificado para essa paciente, por uma profissional que está em formação na especialidade de Ginecologia e Obstetrícia, aprimorando seus conhecimentos e aperfeiçoando a relação médico-paciente.

\section{REFERÊNCIAS}

Bakhtin, M. (2004). Marxismo e filosofia da linguagem. (11.ed.). São Paulo: Hucitec.

Camargo Jr, K.R. A. (1997). Biomedicina. Physis, 7(1), 45-68.

Carson, A., Chabot, C., Greyson, D., Shannon, K., Duff, P., \& Shoveller, J. (2017). A narrative analysis of the birth stories of early-age mothers. Sociology of health \& illness, 39(6), 816-831. https://doi.org/10.1111/14679566.12518

Cassel, C., \& Symon, G. (1994). Qualitative Research in Work Contexts. In: CASSEL, C.; SYMON, G. Qualitative Methods in Organizational Research: A Practical Guide. California: Sage Publications Inc., 3-5.

Charon R., \& Montello M. (2002). Editors. Booth WC. The ethics of medicine, as revealed in literature. Stories matter. The role of narrative in medical ethics. New York: Routledge; 10-20.

Charon, R. (2004). Narrative and medicine [perspective]. N. Engl. J. Med., 350(9), 862-4.

Claro, L.B.L., \& Mendes, A.A.A. (2018). Uma experiência do uso de narrativas na formação de estudantes de Medicina. Interface - Comunicação, Saúde, Educação, 22(65), 621-630. https://doi.org/10.1590/180757622016.0850 . 
Dalfovo, M. S., Lana, R. A., Silveira, A. (2008). Métodos quantitativos e qualitativos: um resgate teórico. Revista Interdisciplinar Científica Aplicada. Blumenau, 2(4), 01-13, Sem II.

De Benedetto M.A.C, \& Gallian D.M.C. (2018). Narrativas de estudantes de Medicina e Enfermagem: currículo oculto e desumanização em saúde. Interface (Botucatu). 22(67), 1197-207.

Dias, M.A.B.(2006). Humanização da assistência ao parto: conceitos, lógicas e práticas no cotidiano de uma maternidade pública. Tese Rev. Ciência e Tecnologia, Rio Grande do Sul, 1(1), 13-20, (Doutorado) Instituto Fernandes Figueira/FIOCRUZ, Rio de Janeiro, RJ.

Diniz,C.S.G.(2005). Humanização da assistência ao parto no Brasil: os muitos sentidos de um movimento. Ciência e Saúde Coletiva, 10(3), 627-637.

Diretrizes nacionais de assistência ao parto normal: versão resumida [recurso eletrônico](2017)/ Ministério da Saúde, Secretaria de Ciência, Tecnologia e Insumos Estratégicos, Departamento de Gestão e Incorporação de Tecnologias em Saúde. - Brasília : Ministério da Saúde.

Favoreto, C.A.O. (2004). A velha e renovada clínica dirigida à produção de um cuidado integral em saúde. In: PINHEIRO, R.; MATTOS, R. (Orgs.). Cuidado: as fronteiras da integralidade. Rio de Janeiro: Hucitec/Abrasco. 205-20.

Frank, A.W. (1995). The wounded storyteller. Chicago: University Chicago Press.

Gil, A.C. (2002). Como elaborar projetos de pesquisa/Antônio Carlos Gil. - (4. ed.) - São Paulo : Atlas.

Gomes, T.A. (2019). Experiências com o Parto: Narrativas das Parturientes do Ceará. Id on Line Rev. Mult. Psic. 13(47), 343-365 - ISSN 1981-1179.

Jamas, M. T., Hoga, L. A. K., \& Reberte, L. M. (2013). Narrativas de mulheres sobre a assistência recebida em um centro de parto normal. Cadernos de Saúde Pública, 29, 2436-2446.

Moreira, D.A. (2002). O método fenomenológico na pesquisa. São Paulo: Pioneira Thomson.

Moura,F.M.J.S.P., Crizostomo,C.D., Nery,I.S., Mendonça,R.C.M., Araújo,O.D., \& Rocha,S.S.(2007). Revista Brasileira de Enfermagem, 60(4), 452- 455.

Porto, A., da Costa, L., \& Velloso, N. (2015). Humanização a Assistência Parto Natural: Uma Revisão Integrativa. Ciência \& Tecnologia, 1(1), 12-19. doi:http://dx.doi.org/10.33053/cientec.v1i1.284

Recomendações da OMS: cuidados durante o parto para uma experiência positiva do parto. Washington, DC: Organização Pan-Americana da Saúde; 2019. Licença: CC BY-NC-SA 3.0 IGO.

Rezende, C. B. (2019). Histórias de superação: parto, experiência e emoção. Horizontes Antropológicos, 25, 203225.

Riessman, C.K. (2008). Narrative methods for the human sciences. Thousand Oaks: Sage Publications. 